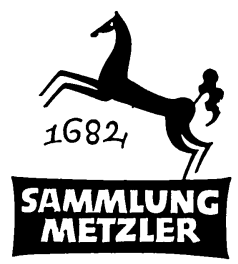

REALIENBUCHER FUR GERMANISTEN A B T. D:

LITERATURGESCHICHTE 
FERDINAND VAN INGEN

\title{
Philipp von Zesen
}

\author{
MCMLXX
}

J. B. METZLERSCHE VERLAGSBUCHHANDLUNG

STUTTGART 
Für Clazien

ISBN 978-3-476-10096-2

ISBN 978-3-476-03827-2 (eBook)

DOI 10.1007/978-3-476-03827-2

\section{96}

(C) Springer-Verlag GmbH Deutschland 1970

Ursprünglich erschienen bei J.B. Metzlersche Verlagsbuchhandlung und Carl Ernst Poeschel Verlag GmbH in Stuttgart 1970 


\section{INHALTSVERZEICHNIS}

I. Blographie . . . . . . . . . . . . . . . . . . . 1

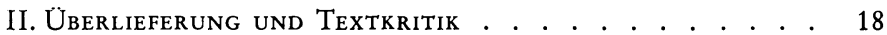

1. Bibliographien . . . . . . . . . . . . . . . . . . . . 18

2. Handschriften, Ausgaben, Briefe . . . . . . . . 21

3. Textkritische Fragen und Datierungsprobleme . . . . . 26

III. DAS WERK . . . . . . . . . . . . . . . . . 34

1. Romane . . . . . . . . . . . . . . . . . . . . . 34

a) Die Romanübersetzungen: "Lysander und Kaliste", »Ibrahim«, »Die Afrikanische Sofonisbe« . . . . . . 42

b) $\gg$ Die Adriatische Rosemund « . . . . . . . . . . . . . 44

c) $»$ Assenat« . . . . . . . . . . . . . . . . . . . 53

d) $\triangleq$ Simson" . . . . . . . . . . . . . . . . 56

2. Lyrik und Schäferdichtung . . . . . . . . . . 58

a) »Melpomene « - b) »Himmlische Kleio« . . . . . . . . 58

c) $\gg$ Hohes Lied« . . . . . . . . . . . . . . . . . 59

d) "Gebundene Lob-Rede von der Buchdrückerey-Kunst « - e) $\gg$ FrühlingsLust« . . . . . . . . . . . . . . 60

f) »Lustinne« . . . . . . . . . . . . . . . . . . . . 61

g) »Dichterische Jugend-Flammen « - h) »Gekreutzigter Liebsflammen Vorschmak« . . . . . . . . . . 62

i) »Schöne Hamburgerin «/»Die Reinweisse Hertzogin« . 63

j) "Dichterisches Rosen- und Liljen-tahl« . . . . . . 64

k) »Lehr-Gesänge von Kristus Nachfolgung " . . . . . 65

1) $\gg$ Kriegs-Lieder - m) »Reise-Lieder « . . . . . . . 66

n) $\gg$ Danklieder" . . . . . . . . . . . . . . . . . . . 67

o) »Prirau/oder Lob des Vaterlandes« . . . . . . . . 67

p) Schäferdichtung . . . . . . . . . . . . . . . . . . . . . . 68

3. Poetologische Werke . . . . . . . . . . . 74

a) Deutscher Helicon" . . . . . . . . . . . . . . 74

b) "Sendeschreiben an den Kreutztragenden «/»Helikonische Hechel« . . . . . . . . . . . . . . . . . . 77

4. Sprachtheoretische Schriften . . . . . . . . 80

a) »Rosen-mând" . . . . . . . . . . . . . . . . . 80

b) Schriften zur Rechtschreibung . . . . . . . . . . . 83

5. Sonstige Schriften . . . . . . . . . . . . . . . . 85

a) Erbauungsschriften . . . . . . . . . . . . . . . 86

b) Historische Schriften . . . . . . . . . . . . . . . . . 888

c) Beschreibung der Stadt Amsterdam . . . . . . . . . . . 89

IV. Die Deutschgesinnete Genossenschaft . . . . . . . . 91

V. Aspekte der Wirkung - Forschungsaufgaben . . . . . 95

Register . . . . . . . . . . . . . 100 


\section{VORBEMERKUNG}

Nach Abschluß des Manuskripts ist es mir eine angenehme Pflicht, allen denen herzlichst zu danken, die mich bei der Vorbereitung und Fertigstellung unterstützt haben. Insbesondere gilt mein Dank Herrn Dr. Herbert Blume, Herrn Dr. Ulrich Maché und Herrn Dr. Volker Meid, auf deren Hilfe ich jederzeit rechnen konnte.

F. v. I.

\section{AbKürZUngen}

AAuL Anzeiger für dt. Altertum u. Literatur

ADB

Allgemeine Dt. Biographie

Amstelodamum Jb. d. Gesellschaft Amstelodamum

dt. deutsch

DVjs.

Deutsche Vierteljahrsschrift für Literaturwissenschaft u. Geistesgeschichte

$\mathrm{Jb}$. Jahrbuch resp. Jaarboek

Jh. Jahrhundert

PBB Beiträge zur Geschichte der dt. Sprache u. Literatur

ZfdB Zeitschrift für dt. Bildung

$\mathrm{ZfdPh}$ Zeitschrift für dt. Philologie 